\title{
Trends in incidence of childhood cancer in Canada, 1992-2006
}

\author{
D. Mitra, MSc; A. K. Shaw, MSc; K. Hutchings, MSc
}

This article has been peer reviewed.

\begin{abstract}
Introduction: Cancer is the leading cause of disease-related death in children aged 1 to 14 years in Canada. Despite the importance to public health of childhood cancer, there have been few reports on Canadian trends published in the peer-reviewed literature. This study examines childhood cancer trends by age, sex, and province of residence using the most current cancer registration data.
\end{abstract}

Methods: Data from the population-based Canadian Cancer Registry were used to compute incidence trends in primary cancers diagnosed between 1992 and 2006 in children (0-14 years) for the 12 major diagnostic groups of the International Classification of Childhood Cancer, 3rd Edition.

Results: Between 1992 and 2006, incidence rates for all cancers remained stable, although trends varied by cancer type. We observed a significant decrease in retinoblastoma in boys for the entire period ( $-6.5 \%$ per year) and an increase in leukemia from 1992 to 1999 $(+3.5 \%$ per year). In girls, there was a significant decrease in renal tumours from 1998 to $2006(-5.7 \%$ per year $)$ and an increase in hepatic tumours from 1997 to $2006(+8.1 \%$ per year). Differences by age and province were also apparent. Some caution should be exercised when interpreting trends involving a small number of cases per year and those with wide $95 \%$ confidence intervals.

Conclusions: Our findings suggest an ongoing need for population-based surveillance and etiologic research.

Keywords: cancer incidence, pediatric, childhood, trends, Canadian Cancer Registry

\section{Introduction}

Several large scale epidemiological studies have reported an increase in the incidence of childhood cancers, particularly leukemia and brain tumours. ${ }^{1-6}$ An increase in the incidence of all childhood cancers combined has also been observed in Europe and the United States, although recent evidence suggests a plateau in rates. ${ }^{7,8}$ It is not clear whether these trends are a real phenomenon or an artefact reflecting changes in diagnostics, case ascertainment, registration practices or differential access to health care.
Although accounting for less than $1 \%$ of all cancers diagnosed in Canada, childhood cancers nevertheless pose a significant burden on child health. ${ }^{9}$ On average, 850 children aged under 15 years are diagnosed with cancer each year in Canada and 135 die of the disease. ${ }^{9}$ Cancer remains the leading cause of disease-related deaths in children aged 1 to 14 years, corresponding to $19 \%$ of deaths between 1992 and $2005 .{ }^{9}$ The Canadian Late Effects Study shows that in addition to personal loss, childhood cancer can negatively impact the finances of affected families due to loss of income, unpaid care-giving and out-of-pocket expenses associated with treatment. ${ }^{10,11}$
Aside from one 1997 study of neuroblastoma, there have been no peerreviewed publications on national childhood cancer incidence trends in Canada. ${ }^{12}$ A complete picture of trends in childhood cancer would allow for monitoring change over time, estimating burden and prompting etiological research, which in turn would provide information on health care needs. In this report, we aim to provide a detailed analysis of the trends in childhood cancer incidence in Canada in relation to sex, age, and regional differences.

\section{Methods}

We used data on cancer incidence from the July 2009 version of the Canadian Cancer Registry (CCR). ${ }^{13}$ This dynamic registry contains information on cases diagnosed from 1992 onward, compiled from reports from all provincial and territorial cancer registries in Canada. The reporting of the CCR is assumed to be complete since each Canadian province and territory has a legislated responsibility to collect and control cancer data. Information is available at the patient level and includes date of birth, sex, province and postal code of residence at diagnosis, date and cause of death as well as cancer characteristics such as date of diagnosis, histology (morphology), site of origin (topography) and behaviour classification. ${ }^{13}$ Our analysis includes CCR data on all malignant tumours diagnosed in children aged less than 15 years between 1992 and 2006. ${ }^{14}$ We based population estimates on quinquennial national censuses conducted from 1986 through 2006; intercensal estimates provided by Statistics Canada were

\section{Author references:}

Centre for Chronic Disease Prevention and Control, Public Health Agency of Canada, Ottawa, Ontario, Canada

Correspondence: Debjani Mitra, Centre for Chronic Disease Prevention and Control, Public Health Agency of Canada, Room 726A4, 785 Carling Avenue, Ottawa, ON K1A 0K9; Tel.: (613) 948-7506; Fax: (613) 960-0944; Email: debjani.mitra@phac-aspc.gc.ca 
used for non-census years. All population estimates have been corrected for census net undercoverage and components of international and interprovincial migration. ${ }^{15}$ All rates were age-standardized using the direct method to the 1991 Canadian population.

We classified childhood cancers according to diagnostic categories of the International Classification of Childhood Cancer, 3rd Edition (ICCC-3), a classification system based on the morphology and topography codes used in International Classification of Diseases for Oncology, 3rd edition (ICD-O-3), ${ }^{16,17}$ and used the same ICCC-3 abbreviated names for cancer categories. The analysis included all cancers in the ICCC-3 classification system except non-malignant intracranial and intraspinal neoplasms, which are not captured by the Canadian Cancer Registry. All age-standardized incidence rates (ASIRs) were extracted and computed using the statistical package SAS EG version 9.1 (SAS Institute Inc.); trends were characterized by calculating annual percent change (APC) and $95 \%$ confidence intervals (CI) using Joinpoint Regression Program, developed by the Surveillance, Epidemiology, and End Results (SEER) Program. ${ }^{18}$ Standard linear regression assumptions used the logarithm for the rate assigned as the dependant variable and the midpoint of the calendar year as the independent variable. Permutation-based joinpoint models were used to assess the magnitude and direction of trends, and a maximum of two joinpoints (allowing a minimum of 5 years between joinpoints) was allowed. Significance was determined by calculating two-sided $p$-values to test the slope of the trend line, using $\alpha=0.05$ as the cut-off for significance. ${ }^{19}$ Age-standardized rates and trends were calculated by diagnosis, sex, age group ( $<1$ year, 1-4 years, 5-9 years, 10-14 years) and province/territory of residence. Neither rates involving fewer than six cases nor trends for cancers with annual rates equal to zero are presented.

\section{Results}

Between 1992 and 2006, 13211 children aged less than 15 years were diagnosed with cancer in Canada, equivalent to an ASIR of 152 cases per million children per year. The most common diagnoses during the 15-year study period were leukemias (32.5\% of all cancers diagnosed in children), central nervous system (CNS) tumours (19.9\%), lymphomas (11.2\%), neuroblastomas $(7.3 \%)$, soft tissue sarcomas $(6.2 \%)$, renal tumours $(5.7 \%)$, and malignant bone tumours $(4.5 \%)$ (Table 1$)$. The remaining histological categories represented approximately $13 \%$ of the total cancer burden in children. The male to female ratio for overall childhood cancer incidence was 1.12 to 1 , and there were marked differences in incidence between age groups. The incidence rate was highest in infants (245 cases per million per year), followed by children between the ages of 1 and 4 (213 cases per million per year), 10 and 14 (120 cases per million per year), and 5 and 9 (116 cases per million per year) (Table 1).

The incidence for all childhood cancers combined remained relatively stable for the duration of the study period (see Table 2); however, trends varied by diagnostic category and sex. Incidence of retinoblastoma decreased significantly for the entire period $(\mathrm{APC}=-2.6 \%$ per year, $95 \% \mathrm{CI}=-4.7$ to -0.4) and of leukemia increased significantly from 1992 to 1999 (APC = $2.4 \%$ per year, $95 \% \mathrm{CI}=0.0$ to 4.9 ). Incidence of retinoblastoma in boys decreased significantly for the entire period (APC $=-6.5 \%$ per year, $95 \% \mathrm{CI}=$ -10.4 to -2.6$)$ and of leukemia increased significantly $(\mathrm{APC}=3.5 \%$ per year, $95 \%$ $\mathrm{CI}=1.3$ to 5.8 ). Corresponding trends were not evident in girls; trends for retinoblastoma showed a modest but nonsignificant decrease and were stable for leukemia. However, incidence of renal tumours in girls decreased significantly between 1998 and 2006 (APC $=-5.7 \%$ per year, $95 \% \mathrm{CI}=-10.7$ to -0.5 ) while that of hepatic tumours increased significantly between 1997 and 2006 (APC = 8.1\% per year, $95 \% \mathrm{CI}=1.8$ to 14.7$)$.

Incidence trends by age (Table 3 ) revealed a significant increase in renal tumours in children aged less that 1 year between 1992 and 1998 (APC $=18.2 \%$ per year, $95 \%$ $\mathrm{CI}=5.3$ to 32.7 ), followed by a period of non-significant trends. Leukemia rates in children aged 1 to 4 years rose modestly but significantly between 1992 and 1999 $(\mathrm{APC}=3.2 \%$ per year, $95 \% \mathrm{CI}=0.3$ to 6.1), decreased (albeit insignificantly) between 1999 and 2002, and then increased significantly again between 2002 and 2006 $(\mathrm{APC}=4.0 \%$ per year, $95 \% \mathrm{CI}=2.7$ to 11.1 ). In children aged 5 to 9 years, there was a rapid increase in carcinomas $(\mathrm{APC}=8.9 \%$ per year, $95 \% \mathrm{CI}=2.2$ to 16.1 ) and germ cell tumours (APC = $10.9 \%$ per year, $95 \% \mathrm{CI}=2.2$ to 20.3 ). In those aged 10 to 14 years, CNS cancers decreased significantly between 1994 and 2004 (APC $=-2.3 \%$ per year, 95\% $\mathrm{CI}=-4.4$ to -0.2$)$. This trend was driven primarily by the decreasing incidence in astrocytomas, which account for over half of the brain tumours in this age group.

We calculated trends for every Canadian province, but not for the sparsely populated territories of Yukon, Northwest Territories and Nunavut. The only province with a significant trend for all cancers combined for the total study period was Alberta $(\mathrm{APC}=1.3 \%$ per year, $95 \% \mathrm{CI}=0.2$ to 2.4), primarily due to increased incidence of leukemia $(\mathrm{APC}=3.1 \%$ per year, $95 \%$ $\mathrm{CI}=0.2$ to 6.1$)$ and lymphoma (APC = $6.5 \%$ per year, $95 \% \mathrm{CI}=1.4$ to 12.0 ). Rates for neuroblastoma also increased but not significantly. Leukemia incidence trends increased significantly in Quebec $(\mathrm{APC}=1.6 \%$ per year, $95 \% \mathrm{CI}=0.1$ to 3.1), while carcinomas, including unspecified malignant epithelial tumours, increased significantly in Ontario (APC = $4.0 \%$ per year, $95 \% \mathrm{CI}=0.0$ to 8.2 ). Intermediate study period analyses found increases in incidence of leukemia in Manitoba between 1996 and 2006 (APC = $3.6 \%$ per year, $95 \% \mathrm{CI}=0.1$ to 7.3 ) and of hepatic tumours in British Columbia between 1992 and 1998 (APC = 12.4\% per year, $95 \% \mathrm{CI}=0.2$ to 25.9 ). Incidence of brain tumours increased in New Brunswick from 1992 to 1998 (APC = $11.9 \%$ per year, $95 \% \mathrm{CI}=3.3$ to 21.1 ) but decreased in Ontario between 1992 and $2004($ APC $=-1.5 \%$ per year, $95 \% \mathrm{CI}=$ -2.8 to -0.1 ). (Additional data available upon request.)

\section{Discussion}

While publications reporting trend data from the mid- to late-1970s found that childhood cancer rates have been increasing at a rate 
TABLE 1

Number of childhood cancer cases ( $0-14$ years) and average age-standardized incidence rate per million by sex and age group, Canada, 1992-2006

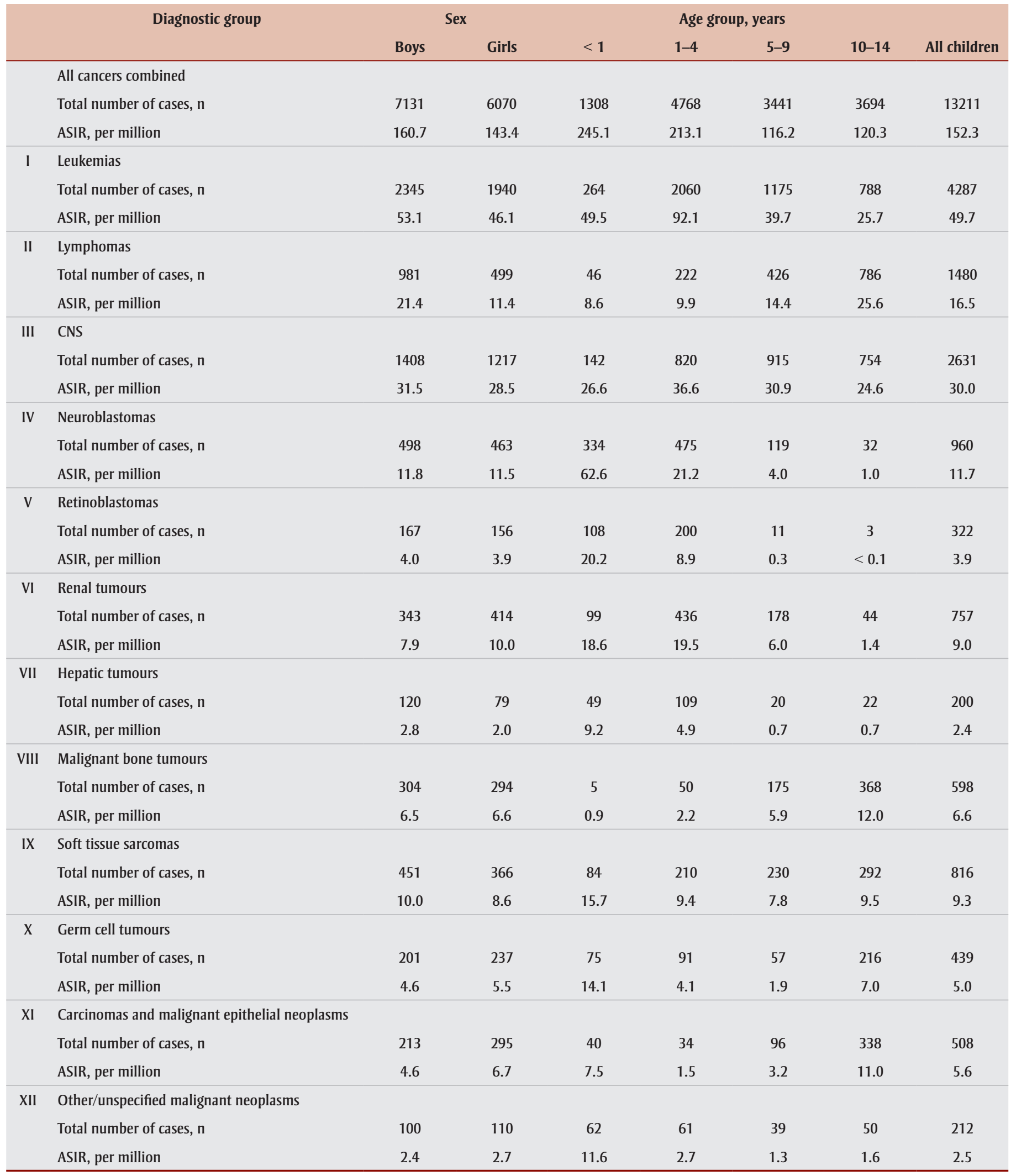

Abbreviations: ASIR, age-standardized incidence rate; CNS, central nervous system.

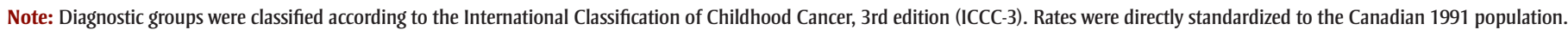


TABLE 2

Trends in childhood cancer (0-14 years) by sex, Canada, 1992-2006

\begin{tabular}{|c|c|c|c|c|c|c|c|}
\hline \multirow{2}{*}{\multicolumn{2}{|c|}{ Diagnostic group }} & \multicolumn{2}{|r|}{ Trend 1} & \multicolumn{2}{|r|}{ Trend 2} & \multicolumn{2}{|r|}{ Trend 3} \\
\hline & & Years & APC $(95 \% \mathrm{Cl})$ & Years & $\mathrm{APC}(95 \% \mathrm{CI})$ & Years & $\mathrm{APC}(95 \% \mathrm{CI})$ \\
\hline \multicolumn{8}{|c|}{ All children } \\
\hline & All cancers combined & 1992-2006 & $0.0(-0.5$ to 0.4$)$ & & & & \\
\hline I & Leukemias & 1992-1999 & $2.4(0.0$ to 4.9$)$ & 1999-2002 & $-4.4(-20.1$ to 14.2$)$ & 2002-2006 & $3.0(-2.6$ to 9.0$)$ \\
\hline II & Lymphomas & 1992-2006 & $0.0(-1.4$ to 1.4$)$ & & & & \\
\hline III & CNS & 1992-2006 & $-0.4(-1.3$ to 0.5$)$ & & & & \\
\hline IV & Neuroblastomas & 1992-2006 & $-0.2(-1.8$ to 1.5$)$ & & & & \\
\hline V & Retinoblastomas & 1992-2006 & $-2.6(-4.7$ to -0.4$)$ & & & & \\
\hline VI & Renal tumours & 1992-2006 & $-1.3(-3.2$ to 0.7$)$ & & & & \\
\hline VII & Hepatic tumours & 1992-2006 & $1.6(-0.8 \text { to } 4.0)^{\mathrm{a}}$ & & & & \\
\hline VIII & Malignant bone tumours & 1992-2006 & $-1.2(-2.8$ to 0.5$)$ & & & & \\
\hline IX & Soft tissue sarcomas & 1992-2006 & $-1.4(-3.6$ to 0.8$)$ & & & & \\
\hline $\mathrm{X}$ & Germ cell tumours & 1992-2006 & $-0.4(-2.2$ to 1.4$)$ & & & & \\
\hline $\mathrm{XI}$ & Carcinomas and malignant epithelial neoplasms & 1992-2006 & $2.5(-0.5$ to 5.6$)$ & & & & \\
\hline XII & Other/unspecified malignant neoplasms & 1992-2006 & $4.6(0.1 \text { to } 9.4)^{\mathrm{a}}$ & & & & \\
\hline \multicolumn{8}{|c|}{ Boys } \\
\hline & All cancers combined & 1992-1999 & $1.1(-0.2$ to 2.3$)$ & 1999-2006 & $-1.5(-2.7$ to -0.3$)$ & & \\
\hline I & Leukemias & 1992-1999 & $3.5(1.3$ to 5.8$)$ & 1999-2002 & $-6.7(-20.6$ to 9.7$)$ & $2002-2006$ & $2.2(-2.9$ to 7.5$)$ \\
\hline II & Lymphomas & 1992-2006 & $0.2(-1.6$ to 2.0$)$ & & & & \\
\hline III & CNS & 1992-2006 & $-0.6(-2.3$ to 1.1$)$ & & & & \\
\hline IV & Neuroblastomas & 1992-2006 & $0.0(-1.9$ to 1.9$)$ & & & & \\
\hline V & Retinoblastomas & 1992-2006 & $-6.5(-10.4 \text { to }-2.6)^{a}$ & & & & \\
\hline VI & Renal tumours & 1992-2006 & $-1.5(-4.6$ to 1.8$)$ & & & & \\
\hline VII & Hepatic tumours & 1992-2006 & $-1.1(-4.0 \text { to } 1.8)^{\mathrm{a}}$ & & & & \\
\hline VIII & Malignant bone tumours & 1992-2006 & $-0.3(-2.9$ to 2.4$)$ & & & & \\
\hline IX & Soft tissue sarcomas & 1992-2006 & $-1.8(-4.8$ to 1.3$)$ & & & & \\
\hline$X$ & Germ cell tumours & 1992-2006 & $-1.1(-3.8$ to 1.6$)$ & & & & \\
\hline $\mathrm{XI}$ & Carcinomas and malignant epithelial neoplasms & 1992-2006 & $3.4(-1.2 \text { to } 8.2)^{a}$ & & & & \\
\hline XII & Other/unspecified malignant neoplasms & 1992-2006 & $8.4(-1.8 \text { to } 19.7)^{\text {a }}$ & & & & \\
\hline \multicolumn{8}{|c|}{ Girls } \\
\hline & All cancers combined & 1992-2006 & $-0.5(-1.1$ to 0.2$)$ & & & & \\
\hline I & Leukemias & 1992-2006 & $0.0(-1.0$ to 1.0$)$ & & & & \\
\hline II & Lymphomas & 1992-2006 & $-0.4(-2.3$ to 1.5$)$ & & & & \\
\hline III & CNS & 1992-2006 & $-0.6(-2.2$ to 0.9$)$ & & & & \\
\hline IV & Neuroblastomas & 1992-2006 & $-1.5(-3.7$ to 0.8$)$ & & & & \\
\hline V & Retinoblastomas & 1992-2006 & $-0.6(-4.0$ to 2.9$)$ & & & & \\
\hline VI & Renal tumours & 1992-1998 & $3.1(-5.2 \text { to } 12.1)^{\mathrm{a}}$ & 1998-2006 & $-5.7(-10.7 \text { to }-0.5)^{a}$ & & \\
\hline VII & Hepatic tumours & 1992-1994 & $55.6(-19.1 \text { to } 199.1)^{a}$ & 1994-1997 & $-16.6(-56.6 \text { to } 60.2)^{a}$ & 1997-2006 & $8.1(1.8 \text { to } 14.7)^{a}$ \\
\hline VIII & Malignant bone tumours & 1992-2006 & $-1.7(-4.5$ to 1.2$)$ & & & & \\
\hline IX & Soft tissue sarcomas & 1992-2006 & $-1.3(-2.9$ to 0.3$)$ & & & & \\
\hline$X$ & Germ cell tumours & 1992-2006 & $0.0(-3.6$ to 3.7$)$ & & & & \\
\hline XI & Carcinomas and malignant epithelial neoplasms & 1992-2006 & $1.9(-1.0$ to 4.9$)$ & & & & \\
\hline XII & Other/unspecified malignant neoplasms & 1992-2006 & $2.2(-2.2 \text { to } 6.8)^{\mathrm{a}}$ & & & & \\
\hline
\end{tabular}

Abbreviations: APC, annual percent change; $\mathrm{Cl}$, confidence interval; CNS, central nervous system.

Note: Significant APC values are bolded. $p<.05$.

${ }^{a}$ Trends involving fewer than 10 cases per year based on rates standardized to the 1991 Canadian population. These should be interpreted with caution. 
TABLE 3

Trends in childhood cancer (0-14 years) by age group, Canada, 1992-2006

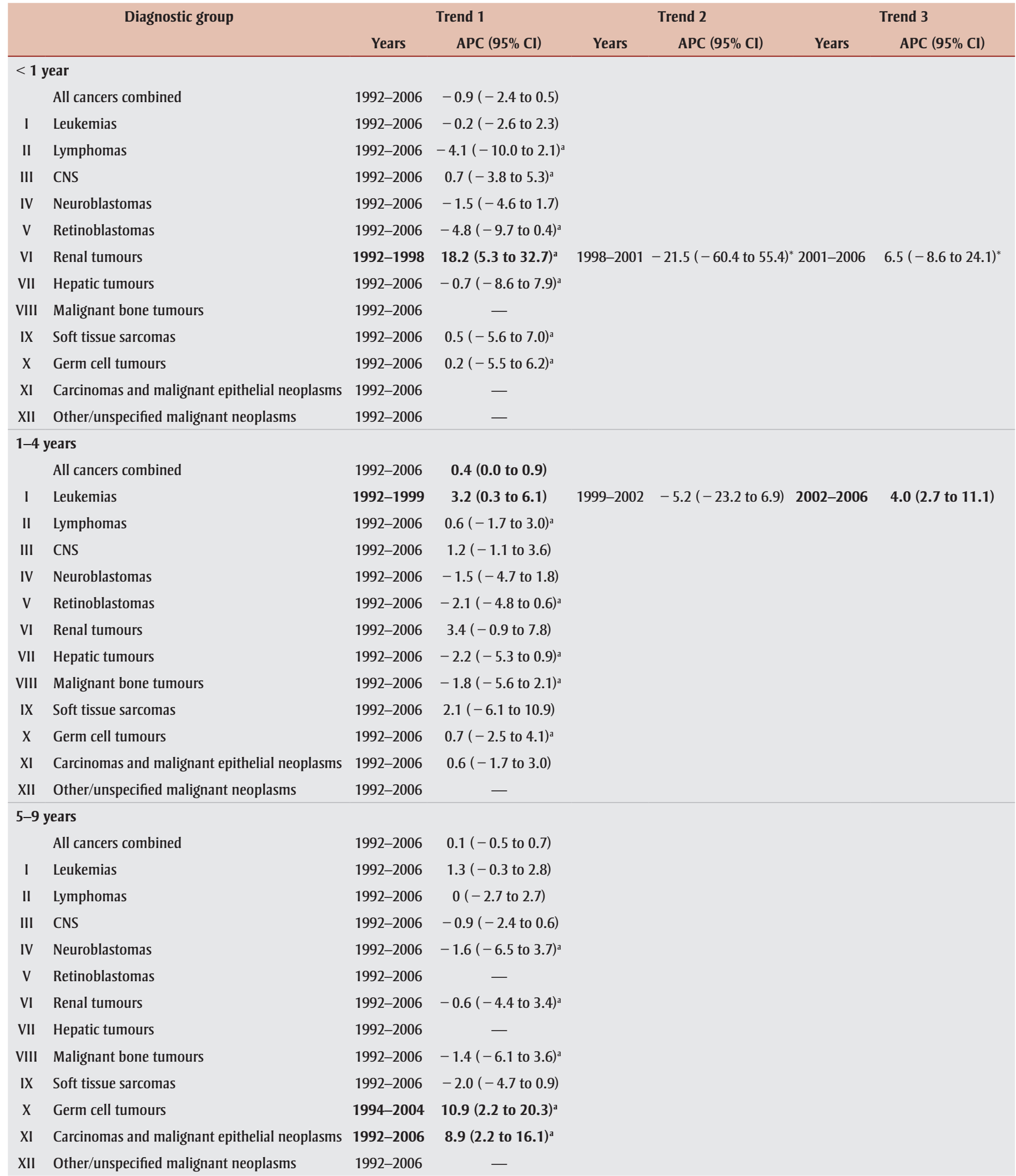


TABLE 3 (continued)

Trends in childhood cancer (0-14 years) by age group, Canada, 1992-2006

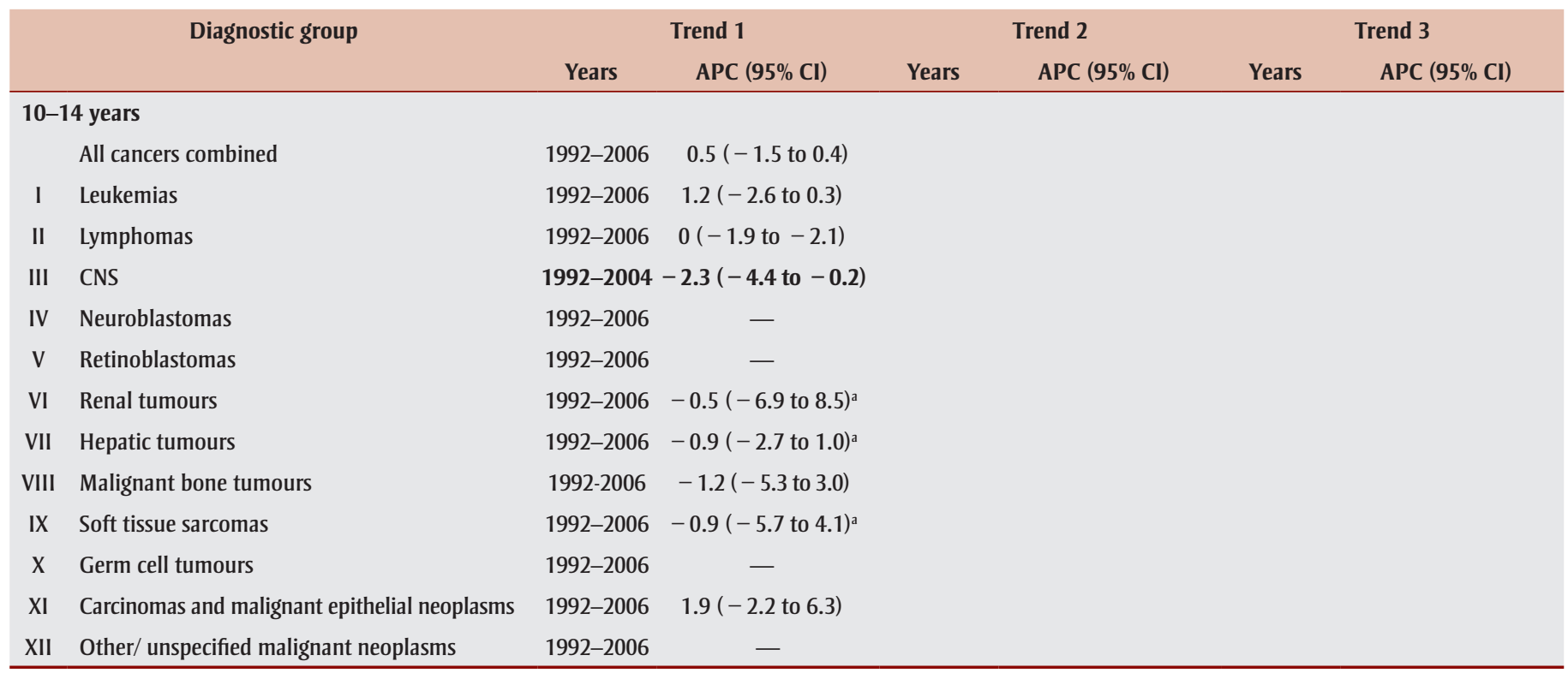

Abbreviations: APC, annual percent change; $\mathrm{Cl}$, confidence interval; CNS, central nervous system.

Note: Significant APC values are bolded. $p<.05$

${ }^{a}$ Trends involving fewer than 10 cases per year based on rates standardized to the 1991 Canadian population. These should be interpreted with caution.

of $0.6 \%$ per year in the United States $(1975-2005)^{20}$ and $1.1 \%$ per year in Europe (1978-1997), ${ }^{21}$ our findings are consistent with those of reports analyzing more recent data from the United States $(1992-2004)^{7}$ and Australia (1983-2007) ${ }^{8}$ showing that incidence rates have been levelling off since the early 1990s.

Our analyses show two significant full-period trends: a decrease in retinoblastoma in boys and an increase in carcinomas in children aged 5 to 9 years. Decreasing retinoblastoma trends in infants, the group most affected by this genetically predisposed cancer, were not significant. In comparison, the most recent research on childhood cancer trends in the United States (1992-2004) 7,22 and Europe (19982007) ${ }^{22}$ shows modest but non-significant increases in incidence of retinoblastoma. The inconsistency with trends observed elsewhere might be due to small numbers of cases. For an extremely rare disease such as retinoblastoma, where the average ASIR over the 15-year study period is 4 cases per million children per year (Table 1), the possibility that the trend may be a chance occurrence due to random fluctuations in annual rates should not be dismissed.
Recent reports from Australia (1983-2006) ${ }^{8}$ and Europe (1978-1997) ${ }^{21}$ confirm our findings of a rapid rise in carcinomas in 5- to 9-year-olds. Improvement in registration alone does not adequately explain this phenomenon since this is likely to yield consistent increases in incidence across all diagnoses unless there is reason to believe that registry-specific practices would lead to under-reporting or over-reporting of a particular diagnosis. Change in tumour classification also does not explain this trend since an exchange in cases between diagnostic groups is not apparent. Descriptive analysis of CCR data shows that carcinoma incidence increases with age and that carcinomas are very rare in Canadian children aged less than 10 years. ${ }^{9}$ It is possible that improvement in diagnostic technologies such as seroassays of tumour markers is inflating the incidence of tumours-previously undetected-in children aged 5 to 9 years, a pattern evident for some subtypes of CNS cancers. ${ }^{23,24}$ The rise in pediatric germ cell cancer incidence in 5- to 9-year-olds that we observed is also supported by data from Australia and Europe. ${ }^{8,21}$ This trend likely reflects a true phenomenon since there have been no changes to diagnostics, coding, registration or screening practices corresponding to the study period. To better understand the factors that underlie this trend, research should examine changes in underlying risk factors associated with germ cell tumours, such as exposure to exogenous estrogen, prenatal exposure to x-rays and parental exposure to chemicals, solvents, or resins. ${ }^{25,26}$

Our results point to several interesting sub-period trends. These include a significant positive trend in leukemia for boys (1992-1999: $\mathrm{APC}=3.5 \%, 95 \% \mathrm{CI}=1.3$ to 5.8) and an insignificant positive trend in hepatic tumours for girls (1997-2006) as well as an insignificant negative trend in renal tumours for girls (1998-2006). A significant decrease in CNS cancers was also evident in older children aged 10 to 14 years (1994-2004: APC $=-2.3 \%$, $95 \% \mathrm{CI}=-4.4$ to -0.2$)$. The modest but significant increase in leukemia between 1992 and 1999 (APC = 2.4, $95 \% \mathrm{CI}=0.0$ to 4.9 ) is compatible with research from Europe ${ }^{22,27}$ and the United States. ${ }^{28}$ As with other changes described earlier, registration artefacts such as changes in coding practices and legislation are likely not associated with this trend; there is little evidence for the former and the latter is refuted by the lack of uniform trends 
across diagnostic categories and sex. Diagnostic interdependence is also an unlikely possibility for this period, and there is no indication that leukemias that would be otherwise captured as lymphomas at a later stage are being captured earlier. Further research should investigate if the positive trends in leukemia specific to boys continue over time and whether they correlate with shifting demographic changes such as the increase in frequency of high birth weight infants in Canada, a phenomenon shown to be positively associated with leukemia and certain types of brain cancers. ${ }^{29-33}$ It is also important to note that the increased trends in leukemia in boys versus girls that we observed has been reported in many regions around the world, ${ }^{34}$ although factors underlying this phenomenon remain largely unsubstantiated. ${ }^{35}$ The rapid increase in unspecified leukemias noted between 1992 and 1999 (in both sexes) implies that a greater number of cases are being grouped in the unspecified category, with the possible result that other leukemia subtypes are being underestimated.

Our study did not have the power to analyse trends in pediatric hepatic cancers by subtype; future research should investigate this given the emerging evidence from some countries that links the rise of hepatoblastoma with increased survival of very low birth weight babies. ${ }^{36,37}$ We found a modest but non-significant increase in hepatic cancers, a trend likely driven by annual increases in rates in girls from 1997 onwards (APC $=8.1 \%$ per year, 95\% $\mathrm{CI}=1.8$ to 14.7 ); however, it is not clear why positive trends were detected in girls but not boys even though this cancer tends to occur at a slightly higher rate in the latter. ${ }^{20,35}$ We could not confirm significant increases in brain cancer incidence recently reported from the United States. ${ }^{7}$ Our data showed stable incidence rates for children aged under 10 years, and significant decreases in 10- to 14-year-olds, a finding that is likely attributed to astrocytomas, a subtype of brain cancer that is known to increase with age. ${ }^{23}$ It is worth noting that our analysis was conducted after the wide-scale availability and adoption of magnetic resonance imaging in clinical practice in North America, a tool partially attributed with the increased diagnosis of low-grade gliomas in the early- to mid1980s in the United States. (The incidence of high-grade gliomas or medulloblastomas, which are more easily detected by computerized tomography scans, did not increase during this period in the United States. ${ }^{1,38}$ ).

Alberta was the only province with a significant increase in the annual incidence rates for all childhood cancers combined $(\mathrm{APC}=1.3 \%, 95 \% \mathrm{CI}=0.2$ to 2.4$)$. Moreover, histology-specific analyses revealed significant positive trends for leukemia in Quebec (APC $=1.6 \%, 95 \%$ $\mathrm{CI}=0.1$ to 3.1$)$ and Alberta (APC $=3.1 \%$, $95 \%$ CI $=0.2$ to 6.1), lymphomas in Alberta $(\mathrm{APC}=6.5 \%, 95 \% \mathrm{CI}=1.4$ to 12.0 ) and carcinomas in Ontario (APC = $4.0 \%, 95 \% \mathrm{CI}=0.0$ to 8.2 ), findings that require investigation in the context of historical changes to registration practices. Although considerable effort has been made to achieve uniformity in defining and classifying new cancer cases in the CCR, reporting procedures and completeness may still vary across the country. The registry in Quebec, for example, relies more heavily on hospitalization data for cancer registration than do other jurisdictions. ${ }^{9}$

Childhood cancer is rare; as a result, trend patterns that appear to be important may in fact be due to random fluctuations. Trends that involve just a few cases per year and those with wide $95 \%$ confidence intervals need to be interpreted cautiously. Statistically significant findings may be due to chance and not real changes in incidence rates. Alternatively, true trends may have also been undetected due random fluctuation in incidence rates. Further, it is difficult to understand how underlying risk factors may be influencing trends since the causes of childhood cancer remain poorly understood. ${ }^{39}$ About 5\% to $15 \%$ of childhood cancers may be attributable to familial and genetic factors and less than $5 \%$ to $10 \%$ to known environmental exposures. ${ }^{40,41}$ While we acknowledge that the observed incidence trends may reflect changes in unknown risk factors or random variation, it is encouraging that the overall rates of childhood cancers have remained relatively stable in Canada over the last two decades. Some sex-specific trends, such as increases in leukemia in boys and hepatic cancers in girls, merit further investigation, as do cancers that are increasing in certain age groups, such as germ cell cancers and carcinomas in 5- to 9-year-olds and CNS cancers in 10- to 14-year-olds.

\section{Acknowledgements}

This research was funded by the Public Health Agency of Canada. The authors gratefully acknowledge the cooperation of the provincial and territorial cancer registries, the national Canadian Cancer Registry maintained by Statistics Canada, and the review of the draft manuscript by Dr. Mark Bernstein, oncologist, from the Isaac Walton Killam Health Centre. The authors disclose that they have no financial or personal incentives with individuals or organizations that could inappropriately influence or bias this research.

\section{References}

1. Linet MS, Ries LA, Smith MA, Tarone RE, Devesa SS. Cancer surveillance series: recent trends in childhood cancer incidence and mortality in the United States. J Natl Cancer Inst. 1999;91:1051-8.

2. Dalmasso P, Pastore G, Zuccolo L, Maule MM, Pearce N, Merletti F, et al. Temporal trends in incidence of childhood leukemia, lymphomas and solid tumors in north-west Italy, 1967-2001. A report of the Childhood Cancer Registry of Piedmont. Haematologica. 2005;90:1197-204.

3. Sharp L, Cotton S, Little J. Descriptive Epidemiology. In: Little J, editor. Epidemiology of Childhood Cancer. No. 149. Lyon (FR): International Agency for Research on Cancer; 1999, p. 10-66.

4. Kenney LB, Miller BA, Ries LA, Nicholson HS, Byrne J, Reaman GH. Increased incidence of cancer in infants in the U.S.: 1980-1990. Cancer. 1998;82:1396-400.

5. Gurney JG, Davis S, Severson RK, Fang JY, Ross JA, Robison LL. Trends in cancer incidence among children in the U.S. Cancer. 1996;78:532-41.

6. Shah A, Coleman MP. Increasing incidence of childhood leukemia: a controversy re-examined. Br J Cancer. 2007;97:1009-12. 
7. Linabery AM, Ross JA. Trends in childhood cancer incidence in the US (1992-2004). Cancer. 2008;112:416-32.

8. Baade PD, Youlden DR, Valery PC, Hassall T, Ward L, Green AC, et al. Trends in incidence of childhood cancer in Australia, 1983-2006. Br J Cancer. 2010;102:620-6.

9. Canadian Cancer Statistics 2008. Toronto (ON): Canadian Cancer Society/National Cancer Institute of Canada; 2010.

10. Shaw AK, Morrison HI, Speechley KN, Maunsell E, Barrera M, Schanzer D, et al. The late effects study: design and subject representativeness of a Canadian, multi-centre study of late effects of childhood cancer. Chronic Dis Can. 2004;25(3-4):119-26.

11. Limburg H, Shaw AK, McBride ML. Impact of childhood cancer on parental employment and sources of income: a Canadian pilot study. Pediatr Blood Cancer. 2008;51(1):93-8.

12. Gao RN, Levy IG, Woods WG, Coombs BA, Gaudette LA, Hill GB. Incidence and mortality of neuroblastoma in Canada compared with other childhood cancers. Cancer Causes Control. 1997;8:745-54.

13. Canadian Cancer Registry [Internet]. Ottawa (ON): Statistics Canada; [modified 2011 Jul 26; cited 2011 Apr 05]. Available at: http://www.statcan.gc.ca/cgi-bin/imdb $/$ p2SV.pl?Function = getSurvey\&SDDS $=3207 \&$ lang $=$ en $\&$ db $=$ imdb\&adm $=8 \&$ dis $=2$

14. History - Canadian Cancer Registry. Ottawa (ON): Statistics Canada; 2007 [cited 2011 Apr 03]. Available at: http://www.statcan.gc.ca/imdb-bmdi /document/3207_D4_T9_V1-eng.pdf

15. Statistics Canada. Demographic Estimates Compendium 2009. Ottawa (ON): Minister of Industry; 2009.

16. Fritz A, Percy C, Jack A, Sobin LH, Parkin $\mathrm{MD}$, editors. International classification of diseases for oncology. 3rd ed. Geneva (CH): World Health Organization; 2000.

17. Steliarova-Foucher E, Stiller C, Lacour B, Kaatsch P. International classification on childhood cancer, 3rd ed. Cancer. 2005;103:1457-1467.
18. Joinpoint Regression Program [computer program]. Version 3.4.2. Bethesda (MD): SEER Program, National Cancer Institute, Statistical Research and Applications Branch; 2010. Available at: http://srab.cancer.gov /joinpoint

19. Kim HJ, Fay MP, Feuer EJ, Midthune DN. Permutation tests for joinpoint regression with application to cancer rates. Stat Med. 2000;19:335-51.

20. Ries LA, Smith MA, Gurney JG, Linet M, Tamra T, Young JL, et al., editors. Cancer incidence and survival among children and adolescents: United States SEER Program 1975-2005. 1st ed. Bethesda (MD): National Cancer Institute; 1999.

21. Kaatsch P, Steliarova-Foucher E, Crocetti E, Magnani C, Spix C, Zambon P. Time trends of cancer incidence in European children (1978-1997): report from the Automated Childhood Cancer Information System project. Eur J Cancer. 2006;42:1961-71.

22. Kaatsch P. Epidemiology of childhood cancer. Cancer Treat Rev. 2010;36:277-85.

23. Smith MA, Freidlin B, Ries LA, Simon R. Trends in reported incidence of primary malignant brain tumors in children in the United States. J Natl Cancer Inst. 1998;90:1269-77.

24. Diamandis EP, Fritche HA, Lilja H, Chan DW, Schwartz MK, editors. Tumor markers: physiology, pathobiology, technology and clinical applications. 1st ed. Washington (DC): AACC Press; 2002.

25. Johnston HE, Mann JR, Williams J, Waterhouse JA, Birch JM, Cartwright RA, et al. The Inter-Regional, Epidemiological Study of Childhood Cancer (IRESCC): case-control study in children with germ cell tumours. Carcinogenesis. 1986;7:717-22.

26. Shu XO, Nesbit ME, Buckley JD, Krailo MD, Robinson LL. An exploratory analysis of risk factors for childhood malignant germ-cell tumors: report from the Childrens Cancer Group (Canada, United States). Cancer Causes Control. 1995;6:187-98.

27. Kroll ME, Draper GJ, Stiller CA, Murphy FA. Childhood leukemia incidence in Britain, 1974-2000: time trends and possible relation to influenza epidemics. J Natl Cancer Inst. 2006;98:417-20.
28. Ries LA, Eisner MP, Kosary CL, Hankey BF, Miller BA, Clegg L, et al., editors. SEER cancer statistics review, 1975-2002 [Internet]. Bethesda (MD): National Cancer Institute; 2005 [cited 2011 Feb 22]. Available from: http://seer.cancer.gov /csr/1975_2002/

29. Ananth CV, Wen SW. Trends in fetal growth among singleton gestations in the United States and Canada, 1985 through 1998. Semin Perinatol. 2002;26:260-7.

30. Hjalgrim LL, Westergaard T, Rostgaard K, Schmiegelow K, Melbye M, Hjalgrim H, et al. Birth weight as a risk factor for childhood leukemia: a meta-analysis of 18 epidemiologic studies. Am J Epidemiol. 2003;158:724-35.

31. Ross JA, Perentesis JP, Robison LL, Davies SM. Big babies and infant leukemia: a role for insulin-like growth factor-1? Cancer Causes Control. 1996;7:553-9.

32. Emerson JC, Malone KE, Daling JR, Starzyk P. Childhood brain tumor risk in relation to birth characteristics. J Clin Epidemiol. 1991;44(11):1159-66.

33. Von Behren J, Reynolds P. Birth characteristics and brain cancers in young children. Int $\mathrm{J}$ Epidemiol. 2003;32(2):248-56.

34. Linet MS, Devesa SS. Descriptive epidemiology of childhood leukaemia. Br J Cancer. 1991;63(3):424-9.

35. Cartwright RA, Gurney KA, Moorman AV. Sex ratios and the risks of haematological malignancies. $\mathrm{Br} \mathrm{J}$ Haematol. 2002;118(4):1071-7.

36. McLaughlin CC, Baptiste MS, Schymura MJ, Nasca PC, Zdeb MS. Maternal and infant birth characteristics and hepatoblastoma. Am J Epidemiology. 2006;162(9):818-28.

37. Tanimura $\mathrm{M}$, Matusui I, Abe J, Ikeda $\mathrm{H}$, Kobayashi N, Ohira M. Increased risk of hepatoblastoma among immature children with a lower birth weight. Cancer Res. 1998;58(14):3032-5.

38. King MA, Newton MR, Jackson GD, Fitt GJ, Mitchell LA, Silvapulle MJ, et al. Epileptology of the first-seizure presentation: a clinical, electroencephalographic, and magnetic resonance imaging study of 300 consecutive patients. Lancet. 1998;352(9113):1007-11. 
39. Ward EM, Thun MJ, Hannan LM, Jemal A. Interpreting cancer trends. Ann N Y Acad Sci. 2006;1076:29-53.

40. Bunin GR. Nongenetic causes of childhood cancers: evidence from international variation, time trends, and risk factor studies. Toxicol Appl Pharmacol. 2004;199:91-103.

41. Lichtenstein $\mathrm{P}$, Holm $\mathrm{N}$, Verkasalo $\mathrm{P}$, Iliadou A, Kaprio J, Koskenvuo M, et al. Environmental and heritable factors in the causation of cancer: analyses of cohorts of twins from Sweden, Denmark, and Finland. N Engl J Med. 2000;343:78-84. 